used-for example, chloramphenicol and metronidazole with or without the addition of penicillin, ampicillin, or co-trimoxazole.

Abscesses of metastatic or cryptogenic origin-These may be streptococcal, or may be caused by a mixture of bacteria. Multiple treatment should be used until bacteriological results are available, after which it may be possible to continue treatment with a single drug.

Spinal and post-traumatic intracranial abscesses-These are usually caused by Staph aureus. Our findings, supported by subsequent clinical experience, suggest that in such cases fusidic acid is the drug of first choice.

Our studies on the penetration of chemotherapeutic agents into intracranial lesions, their activity within such sites, and the clinical effects which they produce are continuing.

The reurosurgical centres participating in the study were: Atkinson Morley's Hospital, London; Frenchay Hospital, Bristol; Regional Centre for Neurosurgery, Romford; St Bartholomew's Hospital, London; Walton Hospital, Liverpool; Wessex Neurological Centre, Southampton. The examining laboratory was Queen Charlotte's Maternity Hospital, London.

This study formed part of a thesis submitted for the degree Doctor of Philosophy in the Faculty of Medicine, University of London.

\section{References}

'Davson, H, and Smith, H V, Proceedings of the Royal Society of Medicine, 1957, 50, 963.

'Garrod, L P, Lambert, H P, and O'Grady, F, Antibiotic and Chemotherapy, p 349. London, Churchill Livingstone, 1973.

Wellman, W E, et al, fournal of Laboratory and Clinical Medicine, 1954 43, 275 .

'Kramer, P W, Griffith, R S, and Campbell, R L, fournal of Neurosurgery, 1969, 31, 295

'Black, P, Graybill, J R, and Charache, P, Journal of Neurosurgery, 1973, 38, 705 .

"de Louvois, J, Gortvai, P, and Hurley, R, British Medical fournal, 1977, 2,981

' de Louvois, J, Thesis for the degree Doctor of Philosophy, University of London, 1977.

de Louvois, J, and Hurley, R, Chemotherapy Progress, 1975, 4, 61

${ }^{9}$ de Louvois, J, and Hurley, R, British Medical fournal, 1977, 1, 998.

"Lithander, A, and Lithander, B, Acta Pathologica et Microbiologica Scandinavica, 1962, 56, 435.

Ingham, H R, et al, Antimicrobial Chemotherapy, 1975, 1, 235.

1.2 Ingham, H R, et al, British Medical fournal, 1975, 4, 39.

${ }^{13}$ George, R H, and Bint, A J, Antimicrobial Chemotherapy, 1976, 2, 100.

"Ingham, H R, Selkon, J B, and Roxby, C M, Antimicrobial Chemotherapy. In press.

${ }^{15}$ Garfield, J, British Medical fournal, 1969, 2, 7

(Accepted 12 September 1977)

\title{
Effect of preoperative anaesthetic visit on anxiety
}

\author{
JULIAN M LEIGH, J WALKER, P JANAGANATHAN
}

British Medical fournal, 1977, 2, 987-989

\section{Summary}

Anxiety levels measured in patients who received preoperative reassurance about anaesthesia from a member of the hospital staff were significantly lower than those in a control group given no such support. Anxiety levels in patients who read a booklet designed to reassure about anaesthesia were less significantly reduced. Owing to the increasing work load in the operating theatre many anaesthetists can no longer afford the time to visit patients preoperatively. This study shows that either this trend should be reversed or the role of reassurer should be assumed by someone else, possibly the anaesthetic nurse. For optimal effect, the visits should be combined with use of the booklet. Unless such measures are taken, up to three million people each year may be being denied any form of reassurance before surgical treatment.

\section{Introduction}

Patients admitted to hospital for surgery naturally experience anxiety, and it has long been generally assumed that a preoperative visit by the anaesthetist reduces apprehension, parti-

St Luke's Hospital, Guildford, Surrey GU1 3NT

JULIAN M LEIGH, MD, FFARCS, consultant anaesthetist

P JANAGANATHAN, FFARCS, senior registrar

University of Surrey, Guildford

J WALKER, MSC, psychologist cularly concerning the outcome of anaesthesia. In our experience, however, with the increasing work load in the operating theatre, anaesthetists are finding less time to undertake such visits. Although medical problems may be dealt with by the surgical houseman, the absence of the anaesthetist's visit may be depriving the patient of a means of reducing preoperative anxiety.

The object of this study was to determine whether the preoperative visit by the anaesthetist was of any value in alleviating anxiety, since its effect had not previously been measured quantitatively. We also hoped to discover whether a specially written booklet, About Your Anaesthetic, might be successfully substituted for these visits, or whether neither of these procedures had any effect on the patient's anxiety.

The comparative effects of a visit by an anaesthetist or a dose of pentobarbitone or both were investigated by Egbert et al, ${ }^{1}$ and the sources of preoperative anxiety were studied by Norris and Baird. ${ }^{2}$ Anxiety may be difficult to estimate ${ }^{3}$ and the patients in those studies were assessed qualitatively as "anxious" or "non-anxious" on a subjective or objective basis. Ramsay, in a study of preoperative fear, used a similar objective-subjective impression approach to determine whether anxiety or fear were present or absent. Simple evaluations of this type rely on personal judgment, however, and do not permit fine discrimination, particularly of mild to moderate grades of anxiety. The Spielberger self-evaluation questionnaire ${ }^{5}$ remedies this and not only enables the patient to estimate the grade of his anxiety level himself but also enables underlying "trait anxiety" (part 1 of the questionnaire) to be distinguished from immediate "state anxiety" (part 2).

Trait anxiety is defined as a basic personality feature. It describes how a person generally feels, and is assumed to be reasonably constant for a given patient. State anxiety is the anxiety level at any particular moment and depends on the environmental factors operating at that time. Spielberger and his colleagues developed this concept of state-trait anxiety 
indices over a number of years, and the test has undergone extensive validation. ${ }^{5}$ The normal index value for trait anxiety is $38+\mathrm{SD} 10$. For state anxiety the normal values are: relaxed circumstances $32 \pm 8$; normal circumstances $37 \pm 10$; examination condition $43+11$; after a stressful cinema film $55 \div 12$. We tested a group of workers in an office and found that they had a trait anxiety score of $34 \cdot 7 \pm 4 \cdot 6$, whereas a group of patients attending a psychiatric outpatient clinic had a trait anxiety score of $46 \cdot 7 \pm 11 \cdot 6$. A group of surgical patients tested 24-48 hours postoperatively had a state anxiety score of 29.5 $4 \cdot 2$.

\section{Patients and methods}

The patients were divided into three groups. In group A state anxiety was assessed before and after a preoperative visit by a representative of the anaesthetist; in group B it was evaluated before and after reading the booklet; and in group $C$ (the control group) it was assessed at similar time intervals to those in groups $\mathrm{A}$ and $\mathrm{B}$, but without the patients being visited by the anaesthetist or given the booklet to read.

To obviate possible bias caused by patients exchanging views or circulating the booklet between the groups we constructed the three groups separately in the order C, A, B from consecutive patients admitted to the relevant wards.

The patients were aged 20 to 60 years, and all had previously had anaesthesia with no ill effects. All were undergoing minor or intermediate procedures, and no operation was for malignant disease. There were equal numbers of men and women in each group. The patients agreed to complete the questionnaires but were not told specifically that we were studying the effects of different managements on anxiety. The two assessments were carried out on the day of operation, well before premedication.

\section{QUESTIONNAIRES}

The first assessment consisted of the Eysenck personality inventory and the Spielberger self-evaluation questionnaire.

Eysenck personality inventory - This evaluates personality in terms of scores for neuroticism and extraversion, together with a "lie" score, which equates with "tendency to exaggerate." This inventory was used to check each group for consistency in personality profile.

Spielberger self-evaluation questionnaire-Part 1 enables basic personality trait anxiety to be evaluated on a $20-80$ score and was used to check the consistency of the groups. Part 2 enables the state anxiety operating when the questionnaire is completed to be evaluated on a 20-80 score. This was the principal measurement in the study.

The second assessment consisted of part 2 of the Spielberger questionnaire only.

\section{BOOKLET}

About Your Anaesthetic consists of 10 pages with about 75 words per page. It was designed to give reassuring information about preoperative preparation, anaesthesia and its safety, the function of anaesthetists, and what to expect postoperatively.

\section{EXPERIMENTAL PROCEDURE}

All patients completed the questionnaires in the first assessment. Those in group A were then visited by "someone from the anaesthetic department" (JW). He gave them the same information that was in the booklet but also discussed matters that were of concern to individual patients. The visit was limited to 10 minutes and contained no physical examination. Group B patients were given the booklet to read, and group $C$ received no information. After about three hours all the patients completed part 2 of the Spielberger questionnaire.

\section{Results}

All data were analysed with the use of non-parametric ranking tests. Within-group comparisons were made with Wilcoxon's test (the non-parametric $t$ test). Between-group data were analysed with the Kruskal-Wallis test (the non-parametric analysis of variance).

There were no significant differences in basic personality indices between the three groups. The respective mean Eysenck personality inventory scores for groups $\mathrm{A}, \mathrm{B}$, and $\mathrm{C}( \pm \mathrm{SD})$ were as follows: for extraversion $10 \cdot 2 \pm 3 \cdot 1,10 \cdot 0 \pm 3 \cdot 9$, and $11 \cdot 1 \pm 4 \cdot 6$; neuroticism $9 \cdot 8 \pm 3 \cdot 5,10 \cdot 4 \pm 4 \cdot 5$, and $12 \cdot 3 \pm 5 \cdot 3$; and lie $1.6 \pm 0.9,1.4 \pm 0.8$, and $1.6 \pm 1 \cdot 0$. The respective mean Spielberger trait anxiety scores were $35 \cdot 3 \pm 6 \cdot 3,38 \cdot 0 \pm 6 \cdot 1$, and $36 \cdot 9 \pm 8 \cdot 1$.

The table gives the Spielberger state anxiety scores. The scores in the first assessment showed no significant difference between the groups (Kruskal-Wallis test statistic $\mathrm{H}=1 \cdot 547$, significance limits 0.9-0.95). Every patient in the study showed a decrease in state anxiety level between the first and second assessments; on average the reduction was $\mathrm{A}>\mathrm{B}>\mathrm{C}$.

Mean Spielberger state anxiety ratings $\pm S D$ in the three groups

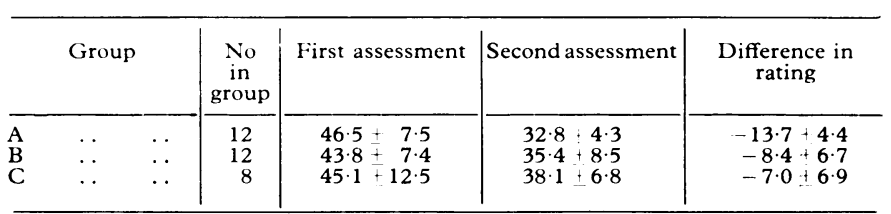

Wilcoxon's test showed that the decrease in anxiety in the controls was not significant $(P>0 \cdot 1)$. The fall in group $B$ was significant at the $2 \%$ level, and the fall in group $\mathrm{A}$ was significant at the $1 \%$ level. A between-group analysis was carried out on the rating differences obtained from the two state anxiety questionnaires. This gave rank sum of group $A=268$ (12 ratings); rank sum of group $B=164_{2}^{1}$ (12 ratings); and rank sum of group $C=95 \frac{1}{2}$ (eight ratings). The KruskalWallis test statistic was $\mathrm{H}=7.59$ with significance limits of between 0.025 and 0.01 , which showed that the different managements produced a significant difference in the reduction of state anxiety between the three groups.

Analysis of the first questionnaires showed that the initial state anxiety scores were consistently high. The second questionnaires showed clearly that a preoperative visit from the representative of the anaesthetist decreased anxiety. They also showed that the booklet was less effective, and that, although there was a decrease in state anxiety among the controls over the same interval, it was not significant. Thus the controls, who received the management prevailing at the time of the investigation, suffered most state anxiety in the preoperative period.

\section{Discussion}

This trial confirmed the clinical view that a preoperative visit by the anaesthetist is beneficial to the patient. The improvement in state anxiety was not necessarily a result of reassurance given solely about anaesthesia, however, as a booklet containing the same information was less effective than the visit.

Since the personal visit was carried out by a non-anaesthetist, patients in group $A$ received no more actual medical information than those in group B. Thus the main effect of the visit was to introduce patients to a sympathetic person who could adopt the reassurances to suit each individual. Presumably similar or increased reductions in the levels of preoperative apprehension would result from talking to the anaesthetist himself, as he is not only sympathetic to personal problems but also understands matters relating to each patient's condition.

It has been estimated that the number of anaesthetics administered in hospitals rose from 1.55 million in 1961 to 2.51 million in $1972,{ }^{6}$ and on this basis the number given in 1977 should be about 3 million. This increase in work load has been met in two ways: firstly, there has been an increase in the number of anaesthetists, and, secondly, the theatre commitment of many individual anaesthetists has been increased to a maximum. Thus in many hospitals the traditional practice of preoperative visiting by anaesthetists is virtually precluded, and 
patients remain anxious until hypnotics, sedatives, tranquillisers, or narcotics are administered for premedication; even then, such treatment may be ineffective.

Egbert et al $^{1}$ " suggestect that patients who had received information during a reassuring, personal visit coped better with preoperative and postoperative stresses and experienced less pain and required fewer analgesics postoperatively, thus implying that recovery was speedier. Cartwright, ${ }^{8}$ however, showed that the successful application of medical expertise depends partly on the patient's feelings about the hospital in which he is being treated and the medical personnel with whom he has contact.

Our findings showed that either the trend away from preoperative visiting by anaesthetists should be reversed or the reassurer's role should be assumed by someone else. In the USA this role is undertaken by the nurse anaesthetist, ${ }^{9}$ and perhaps in Britain it could be assumed by anaesthetic nurses, escort and recovery room nurses, or even operating theatre nurses, as advocated by Welsh and Richardson. ${ }^{10}$ Although we felt that the provision of a cheaper alternative such as the explanatory booklet was reasonable, our study showed that in its present form the booklet was not an adequate substitute for a personal visit even though it did significantly decrease state anxiety levels.

The problem is probably best resolved by using a booklet to provide basic information, and then following this with a visit from an anaesthetic nurse, who can provide more personal reassurance. This combination of both kinds of support is the one most likely to provide an effective reduction in preoperative anxiety.

\section{References}

${ }^{1}$ Egbert, L D, et al, Journal of the American Medical Association, 1963, $185,553$.

${ }^{2}$ Norris, W, and Baird, W L M, British fournal of Anaesthesia, 1967, 39, 503.

${ }^{3}$ Norris, W, British fournal of Anaesthesia, 1969, 41, 778.

${ }^{4}$ Ramsay, M A E, Anaesthesia, 1972, 27, 396.

5 Spielberger, C D, Gorsuch, R L, and Lushene, R E, STAI Manual for the State-Trait Anxiety Inventory ("Self-Evaluation Questionnaire"). Palo Alto, Consulting Psychologists Press, 1970.

${ }^{6}$ Office of Health Economics, Anaesthesia. London, OHE, 1976.

' Egbert, L D, Lamdin, S J, and Hackett, T P, Anesthesiology, 1967, 28, 246.

${ }^{8}$ Cartwright, A, Human Relations and Hospital Care. London, Routledge and Kegan Paul, 1964.

${ }^{9}$ Bunker, J P, The Anesthesiologist and the Surgeon. Edinburgh, Churchill, 1972.

1" Welsh, J, and Richardson, A, National Association of Theatre Nurses News, 1976, 13 (July), 12.

(Accepted 19 August 1977)

\title{
Association of polymyalgia rheumatica and giant-cell arteritis with HLA-B8
}

\author{
B HAZLEMAN, A GOLDSTONE, D VOAK
}

\section{Summary}

Histocompatibility antigens were determined in 30 patients with temporal arteritis, 27 patients with polymyalgia rheumatica, and 216 normal blood donors. HLA-B8 was significantly more common in patients with polymyalgia rheumatica $(59 \%)$ and temporal arteritis $(50 \%)$ than in the controls $(27 \%)$.

The findings of HLA-A10 in $26 \%$ of the patients with polymyalgia rheumatica compared with only $10 \%$ of the controls may be associated with the suggested immunological pathogenesis of the condition.

\section{Introduction}

There is an increasing tendency to regard giant-cell arteritis and polymyalgia rheumatica as being closely related. Giant-cell arteritis remains the only histological abnormality described in

Addenbrooke's Hospital, Cambridge CB2 $2 Q Q$

B HAZLEMAN, MB, MRCP, consultant rheumatologist

University College Hospital, London WC1E 6AU

A GOLDSTONE, MRCP, MRCPATH, consultant haematologist

Regional Transfusion and Immuno-Haematology Centre, Cambridge

D VOAK, PHD, MRCPATH, principal scientific officer polymyalgia rheumatica and widespread vasculitis would explain many of the features of the disease. Familial aggregation of polymyalgia rheumatica, and giant-cell arteritis has been reported by several workers, ${ }^{1-3}$ the relation between the two diseases recently being emphasised again by Liang et al. ${ }^{4}$ Four pairs of first-degree relatives with polymyalgia rheumatica or giant-cell arteritis or both were seen among 250 patients. Two of these pairs were mothers and daughters, and in three of the families the onset of the illness in the two members occurred within 12 months. Polymyalgia rheumatica and giant-cell arteritis are well recognised in England and Scandinavian countries, and in the USA most reports derive from Northern States, especially those with large populations of Scandinavian extraction. Black Americans seem to be rarely affected. ${ }^{j}$

Several recent observations have suggested a possible immunological basis for the disease. Immunoglobulin has been detected in the media of affected arteries ${ }^{6}$; infiltration of the internal elastic lamina by mononuclear cells ${ }^{7}$ has been reported; concentrations of circulating immunoglobulins, especially IgM, may be increased ${ }^{8}$; and increased sensitivity of peripheral blood lymphocytes to human artery and muscle has been found with a lymphocyte transformation test. ${ }^{9}$ We therefore decided to explore any possible association between histocompatibility antigens and polymyalgia rheumatica and giant-cell arteritis.

\section{Patients and methods}

Fifty-seven patients were studied ( 36 women and 21 men; mean age 62 years), 27 of whom had polymyalgia rheumatica, and 30 giantcell arteritis. Polymyalgia was diagnosed clinically, ${ }^{10} 11$ temporal artery biopsy being negative. The diagnosis of giant-cell arteritis was supported in all cases by a temporal artery biopsy. In no patient was rheumatoid factor or antinuclear antibody detected. 